\title{
Passivation Behavior and Surface Resistance of Electrodeposited Nickel-Carbon Composites
}

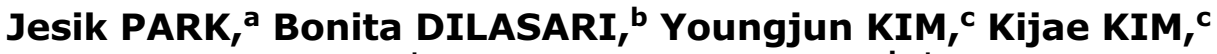 \\ Churl Kyoung LEE, ${ }^{a}$ * and Kyungjung KWON ${ }^{b}$,*
}

\author{
a School of Advanced Materials \& Systems Engineering, Kumoh National Institute of Technology, \\ Gumi, Gyungsangbuk-do 730-701, Republic of Korea \\ b Department of Energy \& Mineral Resources Engineering, Sejong University, Seoul 143-747, Republic of Korea \\ c Advanced Battery Research Center, Korea Electronics Technology Institute, \\ Sungnam, Kyunggi-do 463-816, Republic of Korea
}

*Corresponding authors: cklee@kumoh.ac.kr,kfromberk@gmail.com

\begin{abstract}
Bipolar plates in fuel cells and redox flow batteries are one of the most expensive components, which become a crucial factor for their commercialization. In this report, nickel and carbon are co-electrodeposited from Watts solution containing carbon black powder, and the Ni-C composites are characterized by SEM, EDS, XRD and surface profilometry. The intrinsic passivation behavior and the sheet resistance of $\mathrm{Ni}-\mathrm{C}$ are on a par with pure $\mathrm{Ni}$ when carbon is introduced less than 26 at\% in the composite, but the introduction of carbon to Ni suppresses the increase in sheet resistance after a storage corrosion test, which invites the expectation of high durability as bipolar plate materials. This kind of approach where carbon is introduced to metal-based bipolar plates by electrodeposition can improve the surface properties of pure metal bipolar plates with maintaining their price competitiveness over graphite-based composites and other high cost manufacturing techniques.
\end{abstract}

(c) The Electrochemical Society of Japan, All rights reserved.

Keywords : Nickel, Carbon, Bipolar Plate, Sheet Resistance

\section{Introduction}

In recent years, people are paying more and more attention to the reduced utilization of fossil fuel and the exploitation of alternative energy sources to overcome the global warming issue. Renewable energy such as wind and solar power in addition to fuel cells, which have such a representative type as proton exchange membrane fuel cell (PEMFC), has been a favorite in this regard. Increasing utilization of renewable energy is followed by the development of electrical energy storage systems. Redox flow battery (RFB) is one promising technology for electrical energy storage systems because of its main advantages such as low cost, modularity, transportability, flexibility during charge/discharge cycles, high efficiency and suitability for large scale application. ${ }^{1}$

The thermodynamic open-circuit potential for a single cell of PEMFC is about $1.2 \mathrm{~V}$, which is a similar corresponding value of some types of RFB. ${ }^{2}$ In practical use where higher voltages are needed, cells are connected in series, which is called as a cell stack. In an RFB cell stack as well as a PEMFC stack, a bipolar plate is a component that plays the most significant role in determining the total weight and volume, and the production cost of stack. ${ }^{3}$ Main functions of bipolar plate are to distribute fuel and oxidant (in PEMFC) or electrolytic fluid (in RFB) within the cell; to facilitate water management within the cell; to separate the individual cells in the stack; to carry current away from the cell. $^{4}$

General characteristics required for bipolar plates are:5,6

- good electrical conductivity;

- non-porous and leak-free conduit for fluid;

- provision for stack cooling by water or air;

- good thermal conductivity to achieve stack cooling and satisfactory temperature distribution between cells;

- acceptable corrosion resistance;
- good mechanical stability toward compression forces at low thickness;

- low weight and volume;

- low cost and feasibility for mass production techniques.

The first popular material for bipolar plates is non-porous graphite due to high electrical conductivity and high chemical stability despite the fact that pure graphite is brittle and has poor mechanical resistance. ${ }^{3}$ Various alternative materials such as carbonbased composites and coated metals have been investigated and improved nowadays. Bipolar plates should allow only electricity to pass while keeping the electrolytic fluid inside. ${ }^{7}$ Therefore, the combination of carbon as an electrically conductive material and polymer as a fluid-impermeable material is a favorite option. Major drawbacks of carbon-based composite bipolar plates are they have low mechanical resistance and electrical conductivity compared to metallic bipolar plates. On the other hand, metallic bipolar plates have a fatal problem with their corrosion resistance in operating environments. Moreover, increasing current density during operation would lead to the formation of a passive oxide layer that can protect the bulk metal from the progression of corrosion, which incurs an undesirable effect of high contact resistance that considerably reduces the output electric energy of the cell. ${ }^{8}$

More often than not, the distinctly different advantages of each class of materials have been tried to combine in a form of carbonmetal composites or carbon-coated metals with the minimum usage of carbon. The surface of Ni-based alloys or stainless steel can be modified by carbon ion implantation. ${ }^{9,10}$ Pulsed bias arc ion plating, a process of physical vapor deposition (PVD), was adopted for the formation of carbon film on stainless steel. ${ }^{11}$ Chemical vapor deposition (CVD) was also used for carbon coating on $\mathrm{Ni}$ alloy, $\mathrm{Ti}$ and stainless steel. ${ }^{12-14}$ Although the modification of metallic bipolar plate surface with carbon by the aforementioned techniques has been successful to some degree, the adoption of these techniques 
Table 1. Bath composition and conditions for Ni-C electrodeposition.

\begin{tabular}{c}
\hline Nickel sulfate $\left(\mathrm{NiSO}_{4}\right): 3.2 \mathrm{M}$ \\
\hline Nickel chloride $\left(\mathrm{NiCl}_{2}\right): 0.02 \mathrm{M}$ \\
\hline Boric acid $\left(\mathrm{H}_{3} \mathrm{BO}_{3}\right): 0.65 \mathrm{M}$ \\
\hline Carbon black powder: $0-5 \mathrm{~g} / \mathrm{L}$ \\
\hline $\mathrm{pH}: 4.4$ \\
\hline Temperature: $50^{\circ} \mathrm{C}$ \\
\hline Current density: DC $20 \mathrm{~mA} / \mathrm{cm}^{2}$
\end{tabular}

as a practical manufacturing method for bipolar plates is highly questionable because they require a vacuum ambient, which would lose their price competitiveness.

With the basis of $\mathrm{Ni}$ or Ni alloys, the incorporation of carbon by electroless plating can be a practical approach due to its low manufacturing cost. However, the available composition of electroless plating with $\mathrm{Ni}$ is quite limited as exemplified by Ni-Cu-P/graphite composite coatings. ${ }^{15}$ Putting it all together, the co-electrodeposition of $\mathrm{Ni}$ and carbon could be a promising solution to the practical bipolar plate manufacturing method. Addition of carbon into $\mathrm{Ni}$ plating solution for the formation of composite materials has been proven to endow better mechanical properties besides improving the corrosion resistance. ${ }^{16-18}$ In this study, we investigate the feasibility of Ni-C composite layer as material for bipolar plate, which is produced by electrodeposition from a mixture of Ni Watts solution and carbon black powder. We study the effect of carbon content on surface morphology and corrosion of the Ni-C composite layer. Surface resistance is also evaluated to check the stability to be implemented as bipolar plate material for RFB or PEMFC.

\section{Experimental Procedures}

Ni-C electrodeposition was performed in a typical Watts solution with detailed conditions displayed in Table 1. Highly conductive carbon black (Ketjen black EC-300J from Mitsubishi Chemical with specific surface area $950 \mathrm{~m}^{2} / \mathrm{g}$ ) was used as a carbon source. The information about carbon powder dispersibility in the plating solution was obtained by zeta potential measurement. Zeta potential was measured using ELS (Electrophoretic Light Scattering, Malvern Instruments Ltd, Zetasizer Nano ZS). Carbon black concentration was varied in the range of $0-5 \mathrm{~g} / \mathrm{L}$ in the plating solution to study the effect of carbon concentration on the properties of generated Ni$\mathrm{C}$ composite layer. Analyses of microstructure, corrosion resistance and surface resistance of the $\mathrm{Ni}-\mathrm{C}$ composite layer obtained from each plating condition were conducted.

A copper plate was used as a substrate and a nickel plate as a counter electrode for the electrodeposition. The substrate area was fixed at $1 \mathrm{~cm} \times 1 \mathrm{~cm}$ with $5 \mathrm{~cm}$ distance between the electrodes. The current density was kept constant at $20 \mathrm{~mA} / \mathrm{cm}^{2}$. The solution was stirred during the process to prevent agglomeration, and the temperature was set at $50 \pm 1^{\circ} \mathrm{C}$ using thermostat. The electrodeposition process was immediately conducted after the plating solution was mixed using sonicator for 1 hour in order to make a homogeneous mixture of carbon powder in the solution.

The surface and the cross-section of specimens were observed with FE-SEM (Field Emission Scanning Electron Microscope, JEOL, JSM-6500F), and the carbon content was measured by EDS (Energy Dispersive Spectrometer). The crystal structure and the surface roughness of electrodeposited $\mathrm{Ni}-\mathrm{C}$ composite layers were examined by XRD (X-ray Diffractometer, Rigaku D/MAX-2500) and surface profilometer (Dektak 6M/Veeco), respectively.

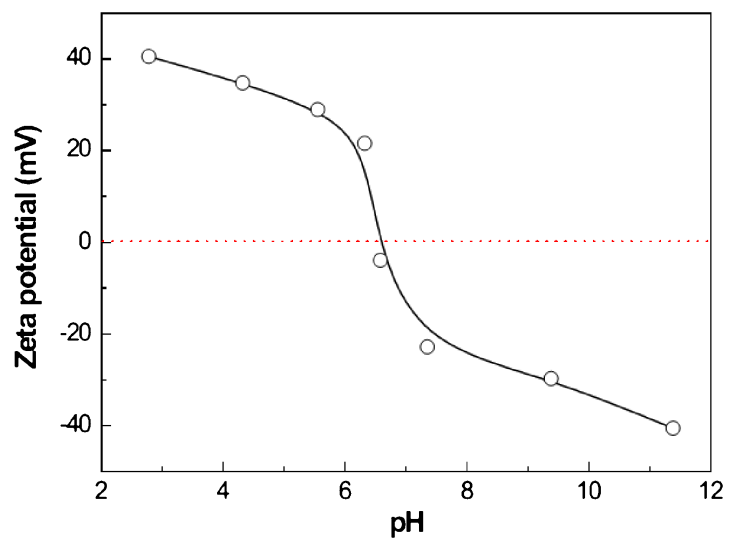

Figure 1. (Color online) Effect of $\mathrm{pH}$ on the zeta potential of carbon black.

The effect of carbon content on corrosion behavior was evaluated by potentiodynamic polarization test using electrochemical corrosion test equipment (Potentiostat/Galvanostat, EG\&G, Model 273) in $5 \%$ sulfuric acid solution at $30^{\circ} \mathrm{C}$. A high density carbon rod was used as a counter electrode and a saturated calomel electrode (SCE) was used as a reference electrode. Anodic polarization tests were carried at room temperature in the potential range of $0.5-1.3 \mathrm{~V}$ vs. $\mathrm{SCE}$ at a scan rate of $3 \mathrm{mV} / \mathrm{s}$. Furthermore, the effect of carbon content on sheet resistance before and after a corrosion test (storage in $50 \%$ sulfuric acid solution at $30^{\circ} \mathrm{C}$ for 1 day) was also investigated by 4-point probe (UK/HL5500PC). The sheet resistance was measured and averaged over five different spots for a specimen, and measured values were scattered within $10 \%$ of the average value. The potentials except zeta potential in this article are reported on the basis of SCE.

\section{Results and Discussion}

The quality of Ni-C composite layer mainly depends on carbon particle stability in the plating solution. Zeta potential, which is a potential at the outer diffusion layer surrounding a particle, is commonly used to evaluate the stability of suspended particles in colloidal systems. A low zeta potential indicates that a medium has a low dielectric constant or a high $\mathrm{pKa}$ with lack of sufficient electrostatic repulsion that can prevent particles from agglomeration. ${ }^{19}$ It is known that zeta potential is affected by the $\mathrm{pH}$ of solution. If a $\mathrm{pH}$ value decreases, the surface potential becomes more positive due to attractive van der Waals force ${ }^{20}$ As the low $\mathrm{pH}$ means more cations are available in the medium, they would be attached on the surface of particles with a negative charge.

The effect of $\mathrm{pH}$ on the zeta potential of carbon black in the Ni-C composite plating solution is shown in Fig. 1. From the curve we could see that an isoelectric point, at which the surface particle net charge is zero and the colloidal system is least stable, is at $\mathrm{pH}$ about 6.5. At $\mathrm{pH}$ values greater than the isoelectric point, the negative surface charge appeared. Typically, agglomeration occurs at potential in the range of $\pm 30 \mathrm{mV}$, which corresponds to $\mathrm{pH}$ values between 5.5 and 9.5 in this curve. The Ni-C composite plating solution would be stable at a $\mathrm{pH}$ value less than 5.5 or greater than 9.5 as sufficient positive or negative charge is present, respectively. Commonly, the desirable $\mathrm{pH}$ for electrolytic Ni composite plating is about $4 .{ }^{21,22}$ From the zeta potential measurement, we could see that the $\mathrm{pH}$ value of 4.4 with zeta potential of $35 \mathrm{mV}$ was an optimum condition for Ni-C composite plating solution. It was confirmed that the selected electroplating condition at the $\mathrm{pH}$ value of 4.4 was suitable so that carbon particles dispersed homogeneously without agglomeration. 


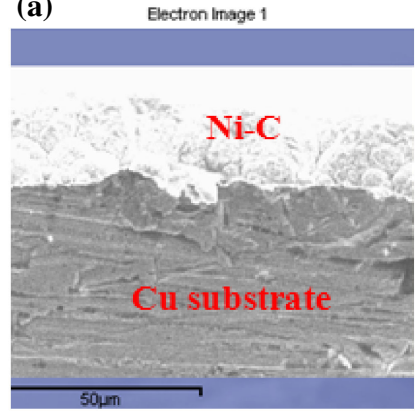

(c)

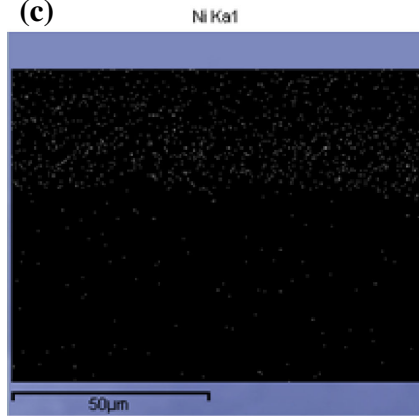

(b)

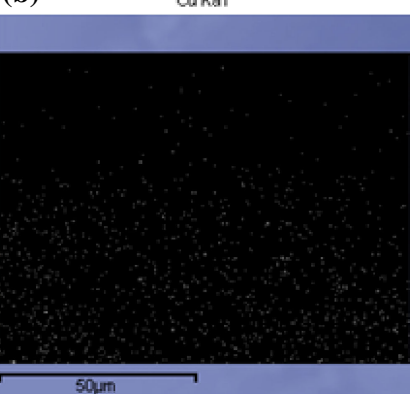

(d)

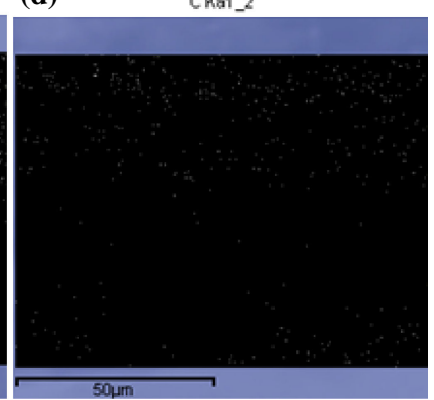

Figure 2. (Color online) EDS elemental mapping on a boundary between the Ni-C composite and the $\mathrm{Cu}$ substrate: (a) SEM image, and the distribution of (b) $\mathrm{Cu},(\mathrm{c}) \mathrm{Ni}$, and (d) $\mathrm{C}$.

EDS mapping was conducted to visualize the dispersion of each element $(\mathrm{Cu}, \mathrm{Ni} \& \mathrm{C})$ near a boundary between the Ni-C composite and the $\mathrm{Cu}$ substrate as shown in Fig. 2. If we match the distribution of $\mathrm{Cu}, \mathrm{Ni}$ and $\mathrm{C}$ with the SEM image [Fig. 2(a)], it could be concluded that $\mathrm{Ni}$ and $\mathrm{C}$ are dispersed fairly homogeneously in the Ni-C composite. Although the EDS analysis showed a direct evidence of carbon incorporation in the composite layers such that plating solutions with $0.5,1.0$ and $5.0 \mathrm{~g} / \mathrm{L}$ carbon concentration generated plating surfaces with 9,13 and 26 at $\%$ carbon content, respectively, it was difficult to confirm the existence of carbon in a SEM analysis. The surface characteristics of $\mathrm{Ni}-\mathrm{C}$ composite layer appear to be affected by the carbon content, and it is known that the increase in carbon concentration in plating solution could incur agglomeration. ${ }^{18,23}$ As a result, the agglomeration of fine carbon particles that adsorb on the plating surface would reduce the interface reaction area by shielding, and lead to the formation of a non-uniform plating layer. Therefore, only when we increased the amount of carbon in Ni-C as high as 26 at $\%$, a seemingly different surface morphology due to a large number of intergranular defects such as pores and cracks was observed. This phenomenon is in accordance with the previous reports where porosity increases with higher carbon black content in the composites. ${ }^{19,24}$

Surface defects in the Ni-C $(26$ at $\%)$ sample were again confirmed through surface roughness measurement in Fig. 3. Embedded carbon particles give a high specific surface area in the electrodeposition of $\mathrm{Ni}$ because they can provide nucleation sites for facilitating crystal growth so that the energy barrier can be reduced. This could result in a dense plating layer of Ni-C composite compared to that of pure $\mathrm{Ni}$ when an optimum amount of carbon black is introduced. However, at relatively high carbon content, agglomeration occurs and produces a non-uniform plating layer with high surface roughness as seen in Fig. 3(d). This level of surface roughness seems to entail a large number of surface defects in the plating layer.

XRD analysis results in Fig. 4 show the crystallinity of obtained layer by electrolytic Ni-C composite plating. The phase of neither amorphous nor crystalline carbon was confirmed, but the presence

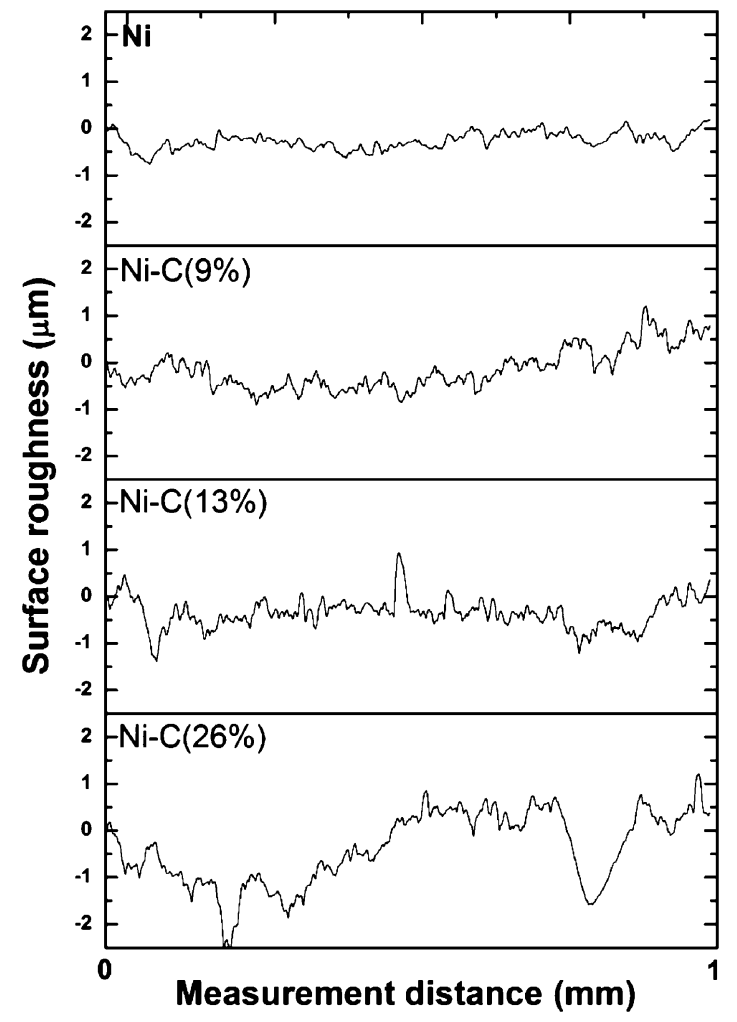

Figure 3. Surface roughness of electrodeposited Ni-C composite layer.

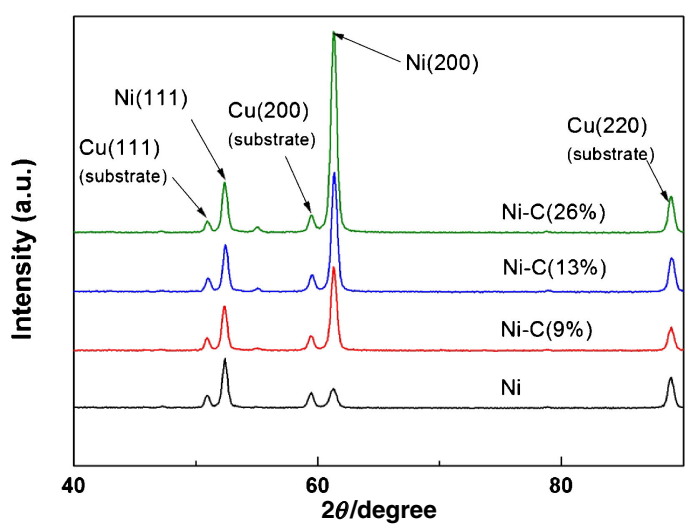

Figure 4. (Color online) XRD patterns of electrodeposited Ni-C composite layer.

of pure crystalline Ni metal was confirmed. On the basis of the theoretical calculations, the initial texture axis of electrodeposited face-centered cubic metals such as $\mathrm{Ni}$ and $\mathrm{Cu}$ should be (111). ${ }^{25}$ Addition of composite particles to the electroplating solution at a low current density and a low $\mathrm{pH}$ value changes the preferred orientation of $\mathrm{Ni}$ grain growth to (100) grains (represented by (200) reflection). ${ }^{26}$ As seen on the XRD results where the preferred orientation of pure $\mathrm{Ni}$ is (111), then it changes to (200) of which peak intensity grows with increasing carbon content. Zhang et al. found that (100) grains have the lowest stress and the lowest strain energy density in a plane of film surface so that the change in preferred orientation from (111) to (100) may be due to the minimization of the strain energy in consideration of the fact that increasing carbon content gives an increase in internal strain of the plating layer. ${ }^{27}$ Meanwhile, the preferred orientation of metal in electrodeposited composites is known to be affected by $\mathrm{pH}$ in local area at electrode-electrolyte interface and also by the properties 


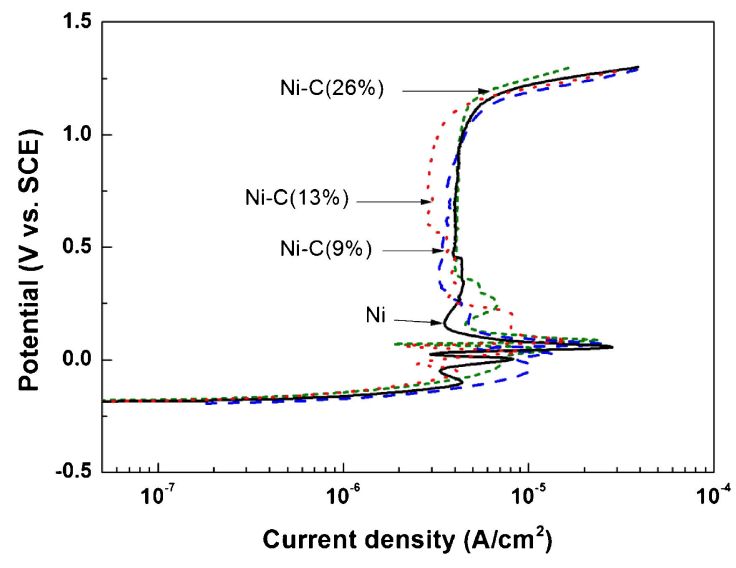

Figure 5. (Color online) Effect of carbon content on anodic polarization of electrodeposited $\mathrm{Ni}-\mathrm{C}$ composite layer.

(surface charge, hydrophilicity/hydrophobicity, etc.) of carbon or ceramic particles adsorbed at the interface. In this experiment, we used Ketjen black that has hydrophilic characteristics as dispersed carbon particles. Interaction of hydrophilic particles with $\mathrm{Ni}$ surface would influence the texture of Ni layer so as to induce the growth of (110) texture and an increase in the amount of (100) oriented grains. By contrast, hydrophobic particles would block a part of surface causing a current decrease and produce new growth centers that result in a smaller $\mathrm{Ni}$ crystal size and a rougher surface. $^{28}$

Figure 5 is the anodic polarization curve for evaluating the corrosion behavior of $\mathrm{Ni}-\mathrm{C}$ composite plating layers in $5 \%$ sulfuric acid solution. Typical anodic polarization behavior of $\mathrm{Ni}-\mathrm{C}$ composite layers is not much different from that of pure $\mathrm{Ni}$ when current densities are normalized by considering the surface roughness of each sample as depicted in Fig. 3. The corrosion potentials of $\mathrm{Ni}-\mathrm{C}$ composite and pure $\mathrm{Ni}$ are approximately $-0.2 \mathrm{~V}$. While the oxidation current is much reduced with showing a stable passivation region in the range of $0.15-1.2 \mathrm{~V}$, trans-passive region develops at potentials higher than $1.2 \mathrm{~V}$. It would be difficult to generalize the trend in the passivity behavior of $\mathrm{Ni}-\mathrm{C}$ of various $\mathrm{C}$ content because the passive currents of the Ni-C composites depend on the potential in the passive region (For example, Ni-C $(13 \%)$ has the lowest passive current at $0.7 \mathrm{~V}$ while it has the highest one at $0.3 \mathrm{~V}$ ). To supplement the potentiodynamic polarization of Fig. 5, the passivation behavior of the $\mathrm{Ni}-\mathrm{C}$ composites was examined by using chronoamperometry in Fig. 6. For example, Ni-C(13\%) has the smallest passive current followed by $\mathrm{Ni}-\mathrm{C}(9 \%)$ while $\mathrm{Ni}$ and $\mathrm{Ni}-$ $\mathrm{C}(26 \%)$ have the similar level of relatively large passive current at $0.7 \mathrm{~V}$ in Fig. 5. This trend is still maintained in the chronoamperometry where potential was stepped from $\mathrm{OCV}$ to $0.7 \mathrm{~V}$ and resulting currents start to stabilize after $30 \mathrm{~s}$. Therefore, it is evident that the magnitude of passive current density in the potentiodynamic polarization shows the same dependence on the amount of $\mathrm{C}$ as the stabilized current density in chronoamperometry. In conclusion, it would be safe to say that the addition of less than a certain level $(\sim 26 \%)$ of carbon to the composite does not change substantially the passivity of $\mathrm{Ni}$, which is a major constituent. Overall, the incorporation of carbon into $\mathrm{Ni}$ can be easily conducted by electrodeposition and the resulting $\mathrm{Ni}-\mathrm{C}$ composite layer shows less passivation current density, which can be a strong point when considered as bipolar plate materials.

Surface electrical resistance, one of the most important properties for usage as bipolar plate materials, was examined and compared for the electrodeposited Ni-C. To investigate the durability issue, a change in sheet resistance before and after a corrosion test (storage in $50 \% \mathrm{H}_{2} \mathrm{SO}_{4}$ at $30^{\circ} \mathrm{C}$ for 1 day) was examined using 4-point probe

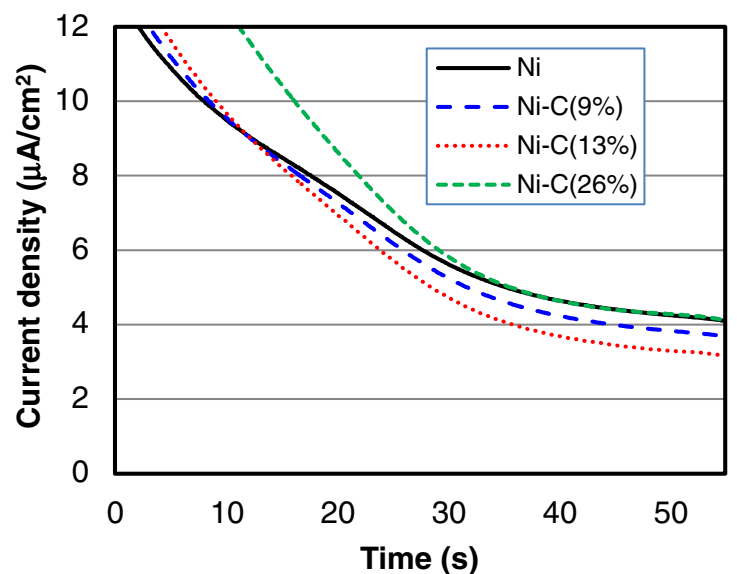

Figure 6. (Color online) Effect of carbon content on chronoamperometry (from OCV to $0.7 \mathrm{~V}$ ) of electrodeposited Ni-C composite layer.
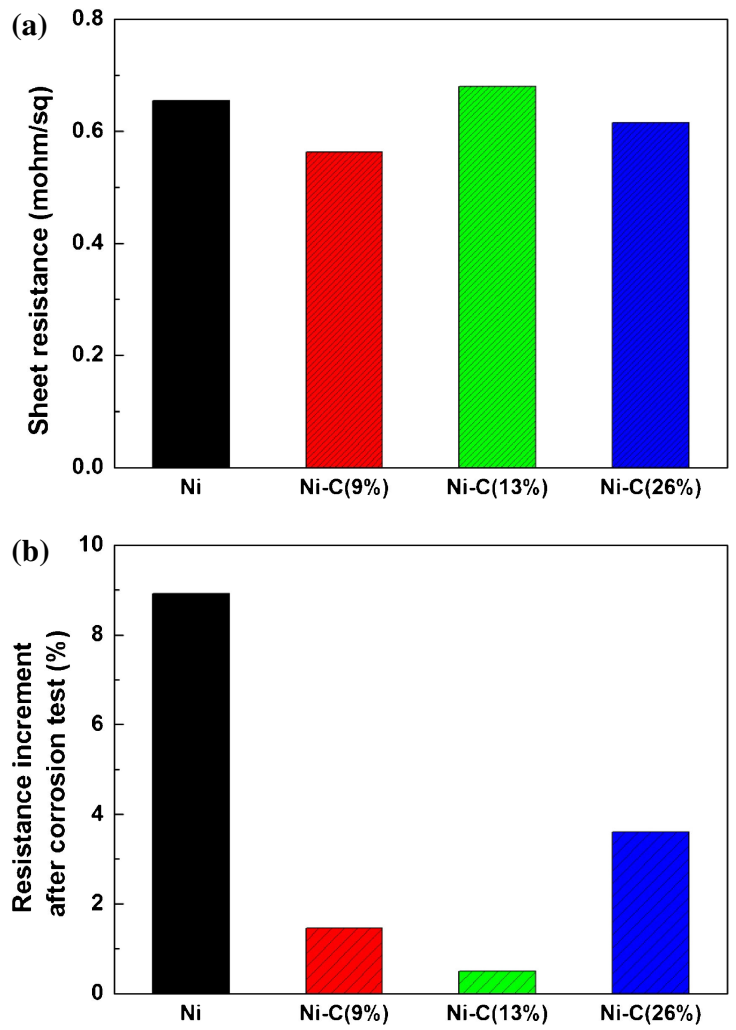

Figure 7. (Color online) Effect of carbon content on (a) the sheet resistance of electrodeposited Ni-C composite layer, and (b) the sheet resistance increment after the corrosion test.

resistance meter. By adopting the 4-point probe method, the intrinsic electrical property of the composite films can be evaluated regardless of their thickness. The sheet resistance of electrodeposited $\mathrm{Ni}-\mathrm{C}$ composite layer as a function of carbon content is displayed in Fig. 7(a) where values are similar to that of Ni. Although there is no remarkable improvement in surface resistance with the incorporation of carbon via co-electrodeposition compared to pure $\mathrm{Ni}$, the stability of Ni-C seems to be superior as seen in Fig. 7(b). In the case of $\mathrm{Ni}$, approximately $9 \%$ of sheet resistance increase was observed after the corrosion test. By contrast, the largest increase in sheet resistance on the $\mathrm{Ni}-\mathrm{C}$ composite layer $(26 \% \mathrm{C})$ is still below $5 \%$. The minimum increase in sheet resistance was observed on $\mathrm{Ni}$ $\mathrm{C}(13 \%)$ with less than $1 \%$ increase after the corrosion test. It is 


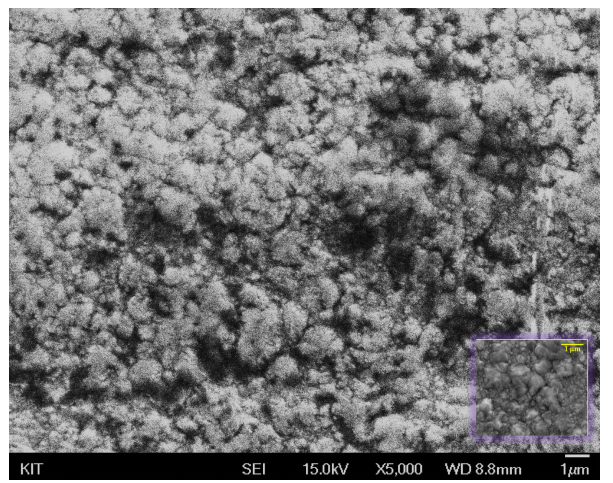

Figure 8. (Color online) SEM images of the Ni-C(13\%) composite before (the inset) and after (the larger image) the corrosion test.

known that the presence of carbon black could minimize an increase in surface resistance and hence maintain the electrical conductivity of composites by providing percolation sites for current. ${ }^{28}$ However, the increase in sheet resistance obtained at higher carbon content could be attributed to non-uniform carbon distribution in the composite plating layer. As we mentioned, high carbon content inevitably leads to agglomeration that forms a non-effective conduction path resulting in an increase in sheet resistance. Therefore, the optimum amount of carbon mixed in the plating solution should be carefully introduced to produce high stability of Ni-C composite layer.

The surface morphology of the Ni-C composites was compared before and after the corrosion (polarization or storage) tests as shown in Fig. 8. Judging from the SEM image comparison between the initial state (the inset) of the composite $[\mathrm{Ni}-\mathrm{C}(13 \%)]$ and the final state (the larger image) after the corrosion tests and the observation that there were no noticeable corrosion evidence and no weight loss, it could be concluded that there was no significant change in surface morphology and neither noticeable corrosion phenomenon on the composite surface. Therefore, we believe that the addition of $\mathrm{C}$ to $\mathrm{Ni}$ hardly changes the passivity of $\mathrm{Ni}$ when $\mathrm{C}$ is introduced less than $\sim 26 \%$.

In summary, we observed that the electrodeposited Ni-C composite layer successfully suppressed the increase in surface resistance after the storage corrosion test compared to $\mathrm{Ni}$. When the optimum carbon content of $\mathrm{Ni}-\mathrm{C}$ is met, the intrinsic passivation behavior and the surface resistance of Ni-C are more favorable to the application to bipolar plate material than Ni. This kind of approach can improve other metal-based bipolar plates with maintaining their price competitiveness over graphite-based composites.

\section{Conclusions}

The incorporation of carbon into Ni was conducted by electrodeposition from Watts solution containing carbon black. Zeta potential measurement determined that $\mathrm{pH}$ value 4.4 is the most preferable condition for Ni-C composite plating solution. XRD analysis revealed that the preferred orientation of pure $\mathrm{Ni}$ was (111), but the addition of carbon black changed the preferred orientation to (200) as a result of interaction between carbon black particles and $\mathrm{Ni}$ surface. When a large amount of carbon black exists in the Ni-C composite layer, a rough surface with numerous pores and cracks developed. The passivation current densities and the sheet resistance of Ni-C composite layers $(9,13$ and $26 \%$ carbon content) show a similar level to those of pure Ni. However, the stability of Ni-C with the optimum carbon content of $13 \%$ seems much improved compared to $\mathrm{Ni}$ judging from the fact that the sheet resistance of $\mathrm{Ni}-\mathrm{C}$ was hardly increased after the storage corrosion test. This suppression of sheet resistance can be attributed to carbon, which could maintain electrical conduction, embedded in $\mathrm{Ni}$ even after $\mathrm{Ni}$ is passivated during the corrosion test.

\section{Acknowledgment}

This work was supported by the Energy Efficiency \& Resources of the Korea Institute of Energy Technology Evaluation and Planning (KETEP) grant funded by the Korea government Ministry of Knowledge Economy (No. 2009T100200074).

\section{References}

1. C. Ponce de Leon, A. Frias-Ferrer, J. Gonzalez-Garcia, D. A. Szanto, and F. C. Walsh, J. Power Sources, 160, 716 (2006).

2. T. Shigematsu, SEI Technical Review, 73, 4 (2011)

3. R. A. Antunes, M. C. L. Oliveira, G. Ett, and V. Ett, Int. J. Hydrogen Energy, 35, $3632(2010)$

4. J. S. Cooper, J. Power Sources, 129, 152 (2004).

5. A. L. Dicks, J. Power Sources, 156, 128 (2006).

6. A. Heinzel, F. Mahlendorf, and C. Jansen, Fuel cells-Proton-exchange membrane fuel cells | Bipolar plates, Encyclopedia of electrochemical power sources (Ed. J. Garche), Elsevier, Amsterdam, p. 810 (2009).

7. N. Tokuda, T. Kanno, T. Hara, T. Shigematsu, Y. Tsutsui, A. Ikeuchi, T. Itou, and T. Kumamoto, SEI Technical Review, 50, 88 (2000).

8. H. Tawfik, Y. Hung, and D. Mahajan, J. Power Sources, 163, 755 (2007)

9. M.-U. Kim, D.-H. Kim, S. Han, E. Fleury, H.-K. Seok, P.-R. Cha, and Y.-C. Kim, Met. Mater. Int., 17, 283 (2011).

10. K. Feng, G. Wu, T. Hu, Z. Li, X. Cai, and P. K. Chu, Surf. Coat. Technol., 206, 2914 (2012).

11. Y. Fu, G. Lin, M. Hou, B. Wu, Z. Shao, and B. Yi, Int. J. Hydrogen Energy, 34, 405 (2009).

12. T. Fukutsuka, T. Yamaguchi, Y. Matsuo, Y. Sugie, and Z. Ogumi, Electrochemistry, 75, 152 (2007)

13. Y. Show, Surf. Coat. Technol., 202, 1252 (2007).

14. C.-Y. Chung, S.-K. Chen, P.-J. Chiu, M.-H. Chang, T.-T. Hung, and T.-H. Ko, J. Power Sources, 176, 276 (2008).

15. C.-K. Lee, J. Power Sources, 220, 130 (2012).

16. P. Martis, V. S. Dilimon, J. Delhalle, and Z. Mekhalif, Electrochim. Acta, 55, 5407 (2010).

17. Z. Yang, H. Xu, Y.-L. Shi, M.-K. Li, Y. Huang, and H.-L. Li, Mater. Res. Bull., 40, 1001 (2005).

18. B.-G. An, L.-X. Li, and H.-X. Li, Mater. Chem. Phys., 110, 481 (2008).

19. R. Xu, C. Wu, and H. Xu, Carbon, 45, 2806 (2007).

20. A. S. Jonsson and B. Jonsson, Sep. Sci. Technol., 31, 2611 (1996).

21. M.-D. Ger, Mater. Chem. Phys., 87, 67 (2004).

22. L. Chen, L. Wang, Z. Zeng, and J. Zhang, Mater. Sci. Eng., A, 434, 319 (2006).

23. X. H. Chen, C. S. Chen, H. N. Xiao, H. B. Liu, L. P. Zhou, S. L. Li, and G. Zhang, Tribol. Int., 39, 22 (2006)

24. P. H. Maheshwari, R. B. Mathur, and T. L. Dhami, J. Power Sources, 173, 394 (2007).

25. V. M. Kozlov and L. Peraldo-Bicelli, Mater. Chem. Phys., 77, 289 (2003).

26. S. Spanou, E. A. Pavlatou, and N. Spyrellis, Electrochim. Acta, 54, 2547 (2009).

27. J.-M. Zhang, Y. Zhang, and K.-W. Xu, J. Cryst. Growth, 285, 427 (2005).

28. R. P. Socha, P. Nowak, K. Laajalehto, and J. Vayrynen, Colloids Surf., A, 235, 45 (2004). 